\title{
Design and Simulation of a Compact Filtenna for 5G Mid-Band Applications
}

\author{
Fatimah K. Juma'a*, Falih M. Alnahwi \\ Electrical Engineering Department, College of Engineering, University of Basrah, Basrah, Iraq
}

\author{
Correspondence \\ * Fatimah Kamil Juma'a \\ Electrical Engineering Department, \\ University of Basrah, Basrah, Iraq. \\ Email: FatimahKamil5353@gmail.com
}

\begin{abstract}
In order to provide an efficient, low cost, and small size radiating structure that passes a certain frequency band with negligible amount of interference, the combination of filters and antennas is proposed to form a single element called filtenna. This paper presents a filtenna element with compact size that can radiates in the $5 \mathrm{G}$ mid-band frequency range $(3.6-3.8 \mathrm{GHz})$ and perfectly rejects all the frequencies outside this range. The filtenna is composed of a printed circuit antenna that is terminated with a crescent shaped stub that is coupled electromagnetically with a miniaturized sharp band-pass filter. The simulation results show a filtenna reflection coefficient with a reduced value within the intended $5 G$ band and with high values along the other unwanted frequencies. Moreover, the structure has an omnidirectional pattern with reasonable gain value within the band of interest, and this makes the antenna very suitable for portable $5 G$ devices.
\end{abstract}

KEYWORDS: band-pass, dual-band, filter, filtenna, monopole antenna.

\section{INTRODUCTION}

With the development of the wireless communication and to achieved large wireless data connection, an antenna is presented as a device that provides a transition between guided electromagnetic waves in wires and electromagnetic waves in free space (transmitting and receiving EM waves) in a prescribed manner [1]. The antenna may be in variety of shapes and sizes by which the frequency band and its EM radiation is determined, such as half elliptic patch [2], hexagon slotted circular monopole antenna [3], 9-shaped monopole antenna [4], star shaped antenna [5], dumbbellshaped slot antenna [6]. Each shape can be used for different applications like Single- band [7], [8], dual band [9], [10], [11], and single-dual band [12], [13].

However, given the nature of most bands and extent interferers, antennas need a tight controller to suppress the interference and to eliminate the unwanted signals where other system exists. The filter is a special device whose distinguishing feature provides a complete or partial suppression of some aspects of the signal, that is, the removal of some undesired frequencies or frequency bands. It is modified to cover the intended rang by using many techniques of stub- loaded multiple mode resonator [14], hairpin filter based on accurate impedance-transforming tapped feeds [15], and stepped-impedance resonator (SIR) dual-band band pass filter (BPF) with selectivityenhancement cells [16].

By referring to the fact that antenna elements are resonators themselves, the filter can be moved and combined within the antenna in single model. This combination (Filter + antenna) achieves many important advantages of wide bandwidth, small electrical size, and an improved performance for frequency selectivity. There are several technics to give filtering antenna, of two edge-coupled filters and two hairpin filters [17], a C-shaped narrow band resonator and an E-shaped wideband resonator [18], and custom- designed coupling probe structures [19], a pair of parasitic elements and pair of slits [20]. This new filtering antenna combination is called Filtenna.

In this paper, a compact and sharp printed circuit filter is combined with a printed circuit antenna that is terminated with a crescent shaped stub to form a filtenna with large selectivity. The resulted filtenna perfectly covers the $5 \mathrm{G}$ mid-band that occupies the frequency range 3.6-3.8 GHz and perfectly rejects all the frequencies outside the intended range of frequencies. Half of the structure of an already designed filter is coupled electromagnetically to the proposed antenna to attain the compactness in the structure. The simulation results verify the perfect frequency coverage for the 5G mid-band applications in term of the reflection coefficient and transmission coefficient. In addition, the

This is an open access article under the terms of the Creative Commons Attribution License, which permits use, distribution and reproduction in any medium, provided the original work is properly cited.

(C) 2021 The Authors. Published by Iraqi Journal for Electrical and Electronic Engineering by College of Engineering, University of Basrah. 
results also show an omnidirectional radiation pattern with reasonable gain value.

\section{FiltenNA DESIGN}

The design of the proposed filtenna is described in this section. The main design goals are: inserting a filtering element that determines the operation frequency range of the antenna with high selectivity, providing a flat gain, and providing good radiation pattern characteristics.

\section{A. Filter Design:}

The design structure consists of two-square Capacitively Loaded Loop (CLL) Based band pass filter similar to that presented in [21]. The composite design is depicted in Fig. 1. It is printed on a Rogers RT5880 substrate with dielectric constant $\left(\varepsilon_{r}\right)$ of 2.2 , a loss tangent $(\delta)$ of 0.009 and thickness (h) of $0.8 \mathrm{~mm}$, and full ground. The following formula estimates the electrical length of the CCL-based filter with respect to the center frequency to the required pass band [22]:

$$
\begin{gathered}
l=\frac{\lambda_{g}}{2}=\frac{c}{2 * f_{c} \sqrt{\varepsilon_{\text {reff }}}} \\
\varepsilon_{\text {reff }}=\frac{\varepsilon_{r}+1}{2}+\frac{\varepsilon_{r-1}}{2}\left[1+12 \frac{h}{W_{p}}\right]^{-1 / 2}
\end{gathered}
$$

where $\lambda_{g}$ is the guided wavelength, $\varepsilon_{\text {reff }}$ is the effective dielectric constant, $W_{p}$ is the patch width. Therefore, the overall length of the L element is equal to $(35.7 \mathrm{~mm})$.

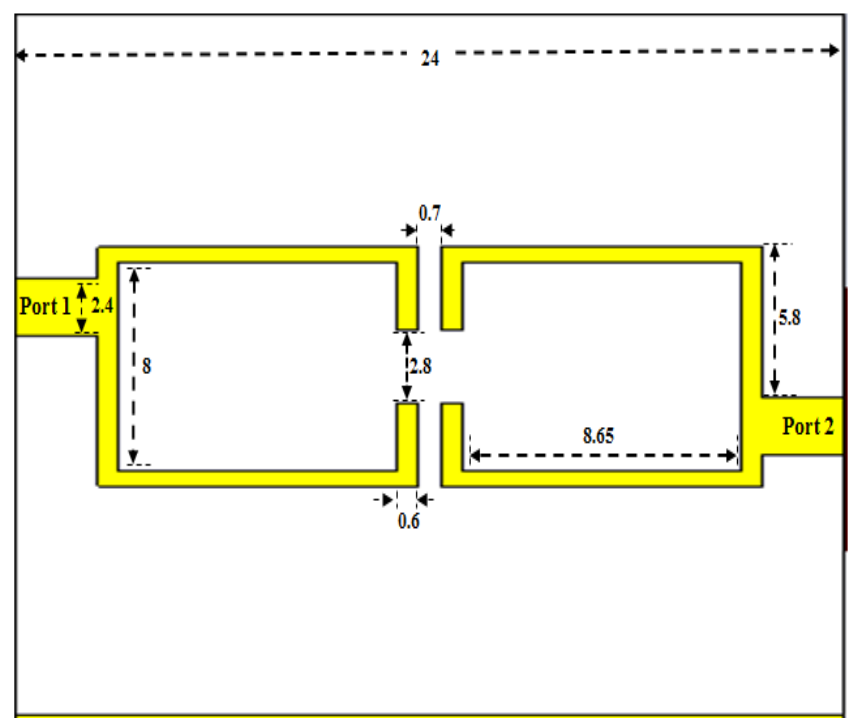

Fig.1. Geometry of the CCLs-based filter (all dimensions are in $\mathrm{mm}$ ).
In Fig.2, the performance of the designed filter is shown. The $\left|S_{11}\right|<-10 \mathrm{~dB}$ coverage includes two resonant frequencies at $3.6 \mathrm{GHz}$ and $3.75 \mathrm{GHz}$ and covers the frequency range from $3.6 \mathrm{GHz}$ to $3.82 \mathrm{GHz}$.

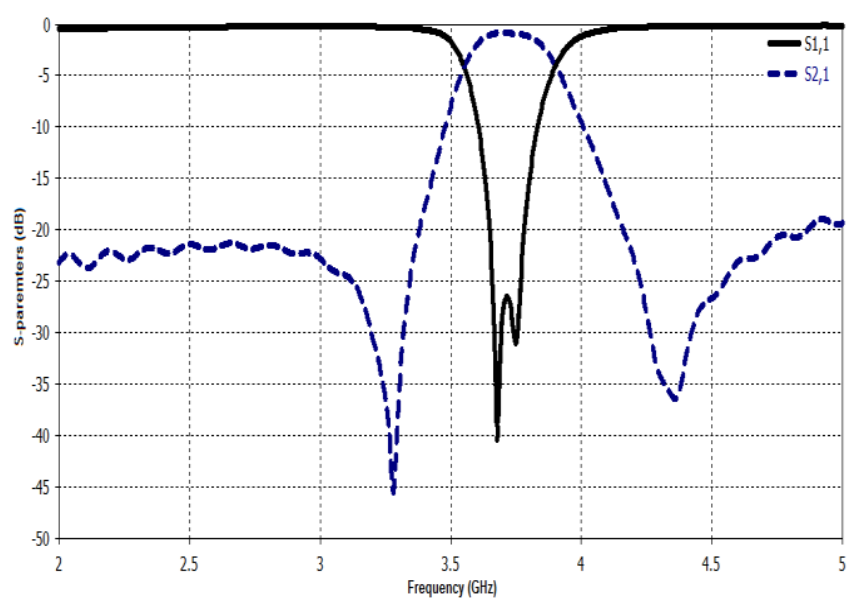

Fig. 2. Simulated of S-parameters of CCLs-based

\section{B. Filtenna Design:}

The design starts with a circular monopole antenna, then it is modified to moon shaped radiating antenna at $3.7 \mathrm{GHz}$ with radius of $(\mathrm{R})$. By replacing the second half of the CLLbased filter with antenna as a parasitic element, the proposed filtenna is presented. As mentioned earlier, the dielectric substrate of the proposed filtenna is Rogers RT5880 substrate with dielectric constant $\left(\varepsilon_{r}\right)$ of 2.2 , a loss tangent ( $\delta$ ) of 0.009 and thickness (h) of $0.8 \mathrm{~mm}$, and overall size 27 $\mathrm{mm} * 24.2 \mathrm{~mm}$ as demonstrated in Fig. 3. It is fed by a $50 \Omega$ microstrip feed line whose characteristic impedance is given by the following formula [1]:

$$
Z_{c}=\frac{120 \pi}{\sqrt{\varepsilon_{\text {reff }}}\left[\frac{W_{f}}{h}+1.393+0.667 \ln \left(\frac{W_{f}}{h}+1.444\right)\right]}
$$

where $W_{f}$ denotes the width of the feed line, and $h$ is the height of the substrate. The electrical length of the monopole antenna with respect to the center frequency [22]:

$$
\begin{aligned}
l=\frac{\lambda_{g}}{4} & =\frac{c}{2 * f_{c} \sqrt{\varepsilon_{r e}}} \\
\varepsilon_{r e} & =\frac{\varepsilon_{r}+1}{2}
\end{aligned}
$$

$\varepsilon_{r e}$ is the effective dielectric constant of monopole antenna.

The optimized parameters of the proposed filtenna are given in Table I. 


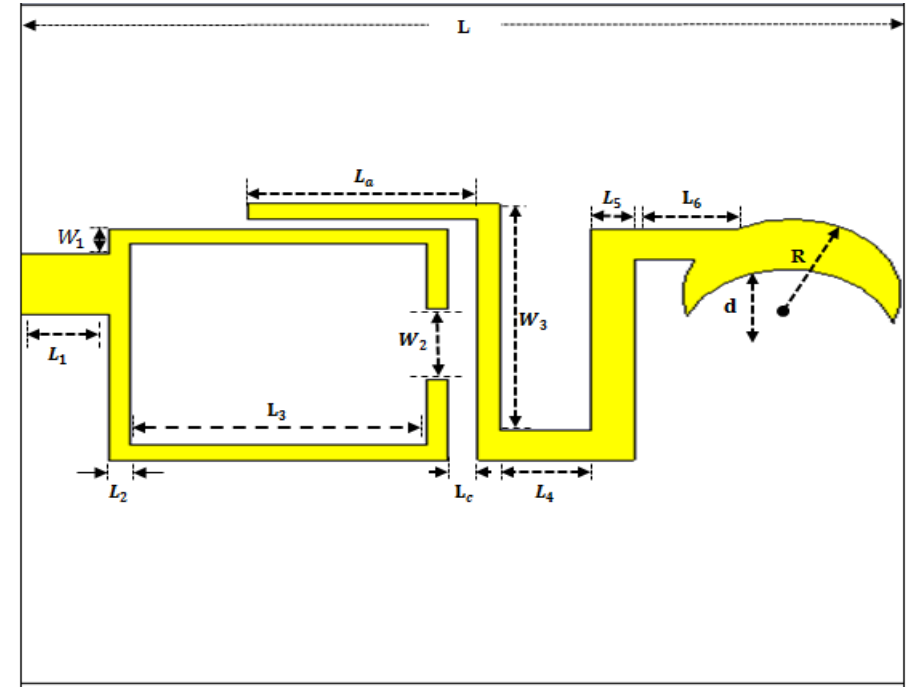

(a)

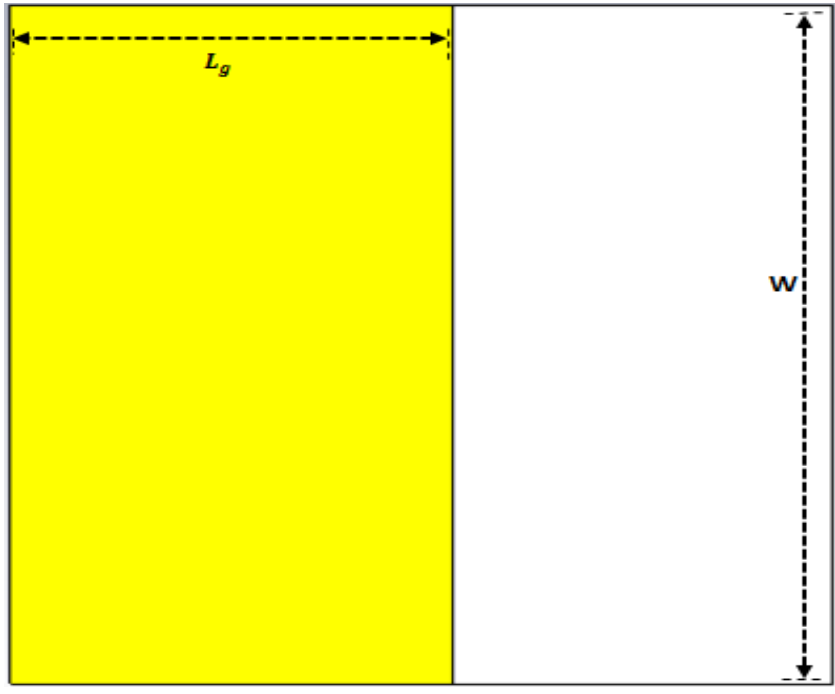

(b)

Fig. 3. Geometry of the proposed filtenna. (a) Top view (b) Back view

TABLE I

The Optimized Design Parameters of the Presented Filtenna.

\begin{tabular}{|c|c|c|c|}
\hline Parameter & $\begin{array}{c}\text { Dimension } \\
(\mathrm{mm})\end{array}$ & Parameter & $\begin{array}{c}\text { Dimension } \\
(\mathrm{mm})\end{array}$ \\
\hline$L$ & 24.2 & $L_{5}$ & 1.2 \\
\hline $\mathrm{W}$ & 27 & $\mathrm{~L}_{6}$ & 3.05 \\
\hline$L_{g}$ & 13 & $\mathrm{~L}_{a}$ & 5.09 \\
\hline $\mathrm{R}$ & 3 & $\mathrm{~d}$ & 3.8 \\
\hline$L_{1}$ & 3.6 & $\mathrm{~L}_{c}$ & 0.72 \\
\hline$L_{2}$ & 0.6 & $W_{1}$ & 1 \\
\hline $\mathrm{L}_{3}$ & 8.09 & $\mathrm{~W}_{2}$ & 2.8 \\
\hline$L_{4}$ & 2.49 & $\mathrm{~W}_{3}$ & 9 \\
\hline
\end{tabular}

\section{Parametric STUdy}

In this section, the effects of different fundamental parameters $\left(L_{a}, L_{g}, L_{c}\right.$, and d) on the filtenna reflection coefficient are shown in Figs. 4 (a) through (d). In Figs 4(a) and (b), the reflection coefficient characteristics of the filtenna can be tuned by modifying the position of the resonant frequencies. The values of $L_{a}=5.09 \mathrm{~mm}$ and $\mathrm{d}=$ $3.8 \mathrm{~mm}$ provides the suitable locations of the resonant frequencies so that the intended $5 \mathrm{G}$ mid-band is covered perfectly. In addition, the change in $L_{a}$ dramatically affects the filtenna matching and the bandwidth, while the variation of d just influences the bandwidth. It is observed from Figs. 4 (c) and (d) that the bandwidth and impedance-matching characteristics of the filtenna at both resonant frequencies are strongly dependent on the value of $L_{g}$ and $L_{c} . L_{g}=13 \mathrm{~mm}$ and $L_{c}=0.72 \mathrm{~mm}$ are so suitable to set the filtenna reflection coefficient below $-10 \mathrm{~dB}$ with better impedance matching along the desired frequency range $(3.56 \mathrm{GHz}$ to $3.8 \mathrm{GHz})$.All optimized parameters are obtained using the CST Microwave Studio software [23].

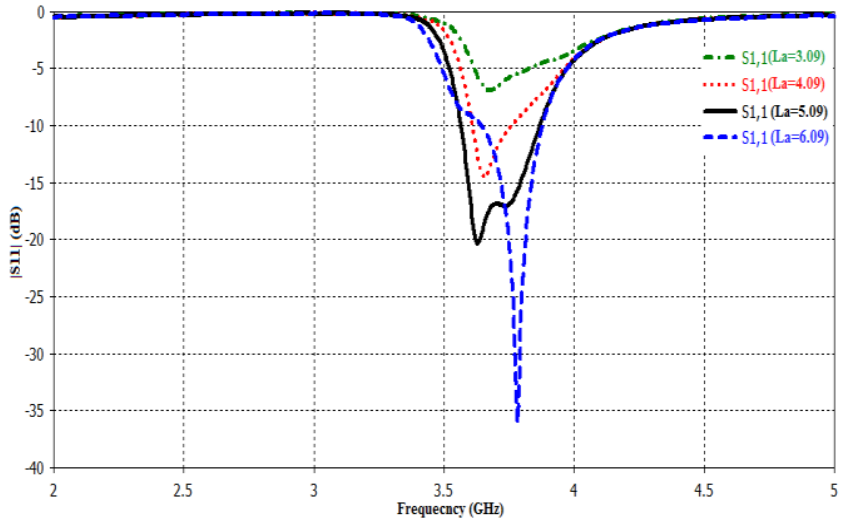

(a)

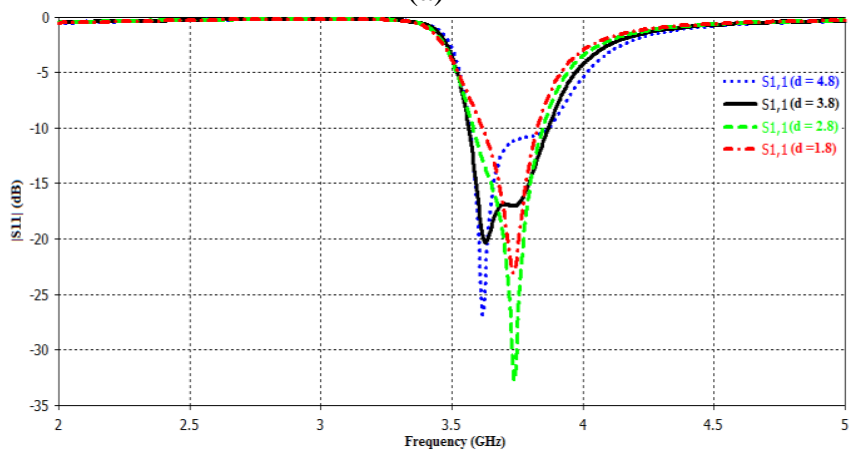

(b)

Fig.4. Antenna reflection coefficient for the moon shaped filtenna at (a) d=3.8mm, $L_{g}=13 \mathrm{~mm}, \mathrm{~L}_{c}=0.72 \mathrm{~mm}$, and different values of $\mathrm{L}_{a}$, (b ) $\mathrm{L}_{a}=6 \mathrm{~mm}, L_{g}=13 \mathrm{~mm}, \mathrm{~L}_{c}=$ $0.72 \mathrm{~mm}$, and different values of $\mathrm{d}$, (c) $\mathrm{L}_{a}=6 \mathrm{~mm} \mathrm{~d}=3.8 \mathrm{~mm}$, $L_{c}=0.72 \mathrm{~mm}$, and different values of $L_{g}$, and (d) d=3.8mm, $\mathrm{L}_{a}=6 \mathrm{~mm}, L_{g}=13 \mathrm{~mm}$, and different values of $\mathrm{L}_{c}$. 


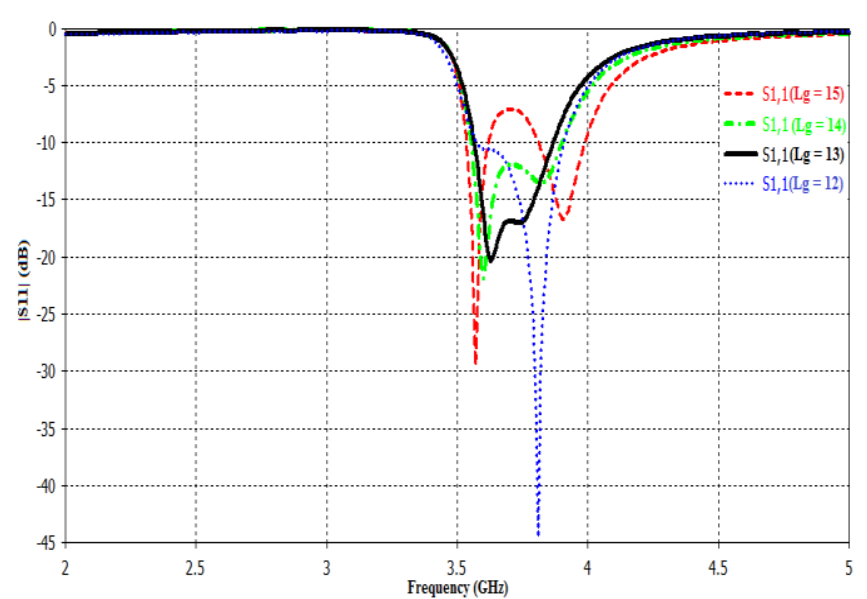

(c)

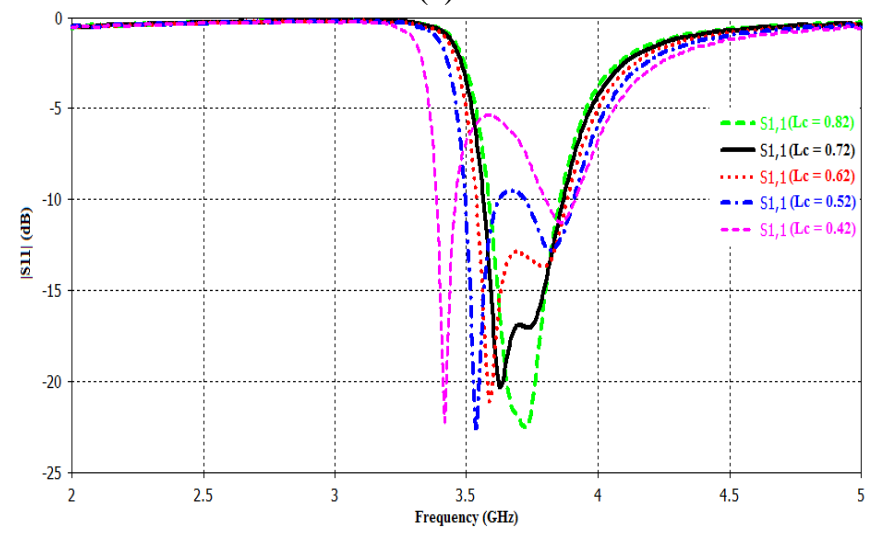

(d)

Fig.4. Continued.

\section{SiMULATION RESULTS}

The simulated reflection coefficients of the antenna with and without filter are shown in Fig.5. The proposed antenna has a bandwidth of $3.7 \mathrm{GHz}$ (from $3.36 \mathrm{GHz}$ to $4.2 \mathrm{GHz}$ ). The fitenna (antenna with filter) shows dual resonant frequencies at $3.63 \mathrm{GHz}$ and $3.75 \mathrm{GHz}$, respectively. Two resonance frequencies are close to each other so that they show a broad bandwidth characteristic from $3.56 \mathrm{GHz}$ to $3.8 \mathrm{GHz}$. It effectively suppresses the unwanted signals out of the $5 \mathrm{G}$ mid-band. It is clear that the CCL-base filter can be modified as a filtenna by which it is followed by an antenna having resonant frequency that encompasses with the pass band of the filter.

In Fig. 6, the current distribution of the filtenna is shown in order to understand the radiation mechanism at each resonant frequency. It is clear that the current is mainly concentrated over all antenna arms and the top part of CLL element at 3.7GHz as shown in Fig. 6. (a). On the other hand, Fig. 6(b) exhibits that the current is concentrated around the filter arms at $3.86 \mathrm{GHz}$, and a negligible amount at the antenna because the frequency $3.86 \mathrm{GHz}$ is outside the bandwidth of the proposed filtenna. In other words, outside the frequency coverage of the filtenna, the energy is stored within the filter rather than radiating via the antenna.

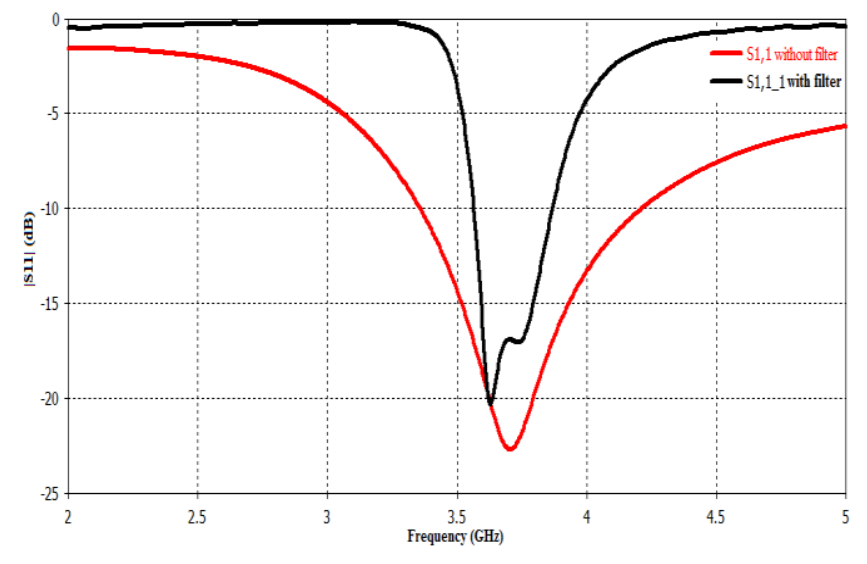

Fig. 5. Simulation reflection coefficient of the proposed filtenna with and without filter.

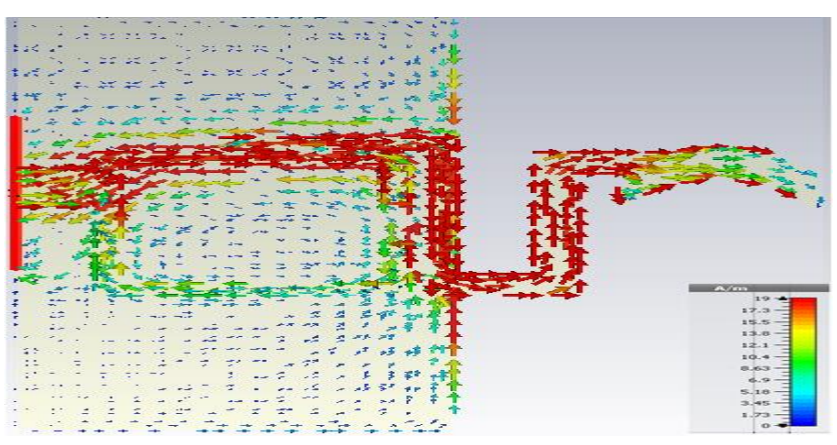

(a)

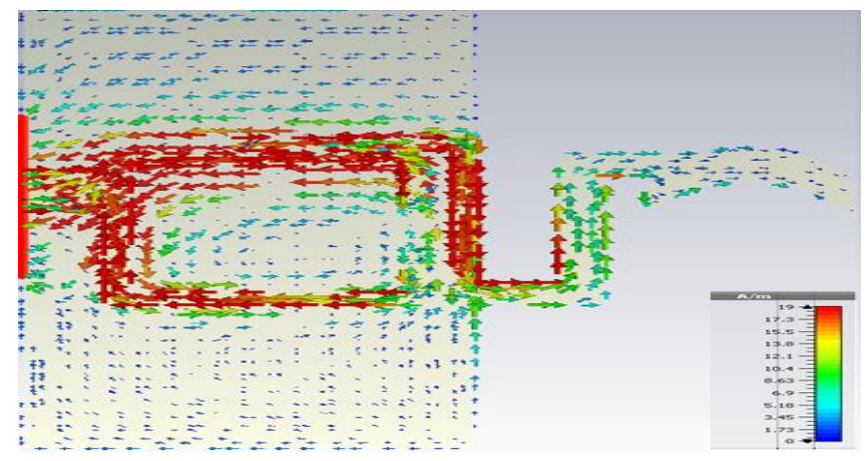

(b)

Fig. 6. Simulation current distribution (a) at $3.7 \mathrm{GHz}$ and (b) at $3.86 \mathrm{GHz}$.

The simulated 2D-polar power patterns of the filtenna at $3.7 \mathrm{GHz}$ are illustrated in Figs. 7. (a) and (b), respectively. It is clear that the filtenna provides good radiation characteristics with a bidirectional power pattern shape in the E-plane, a stable omnidirectional radiation patterns in $\mathrm{H}$ plane, and gain value of $2.923 \mathrm{dBi}$.

Table $\Pi$ presented a comparison between proposed filtenna and some other filtennas in terms of dielectric constant $\varepsilon_{r}$ and the overall size $L * W$. 

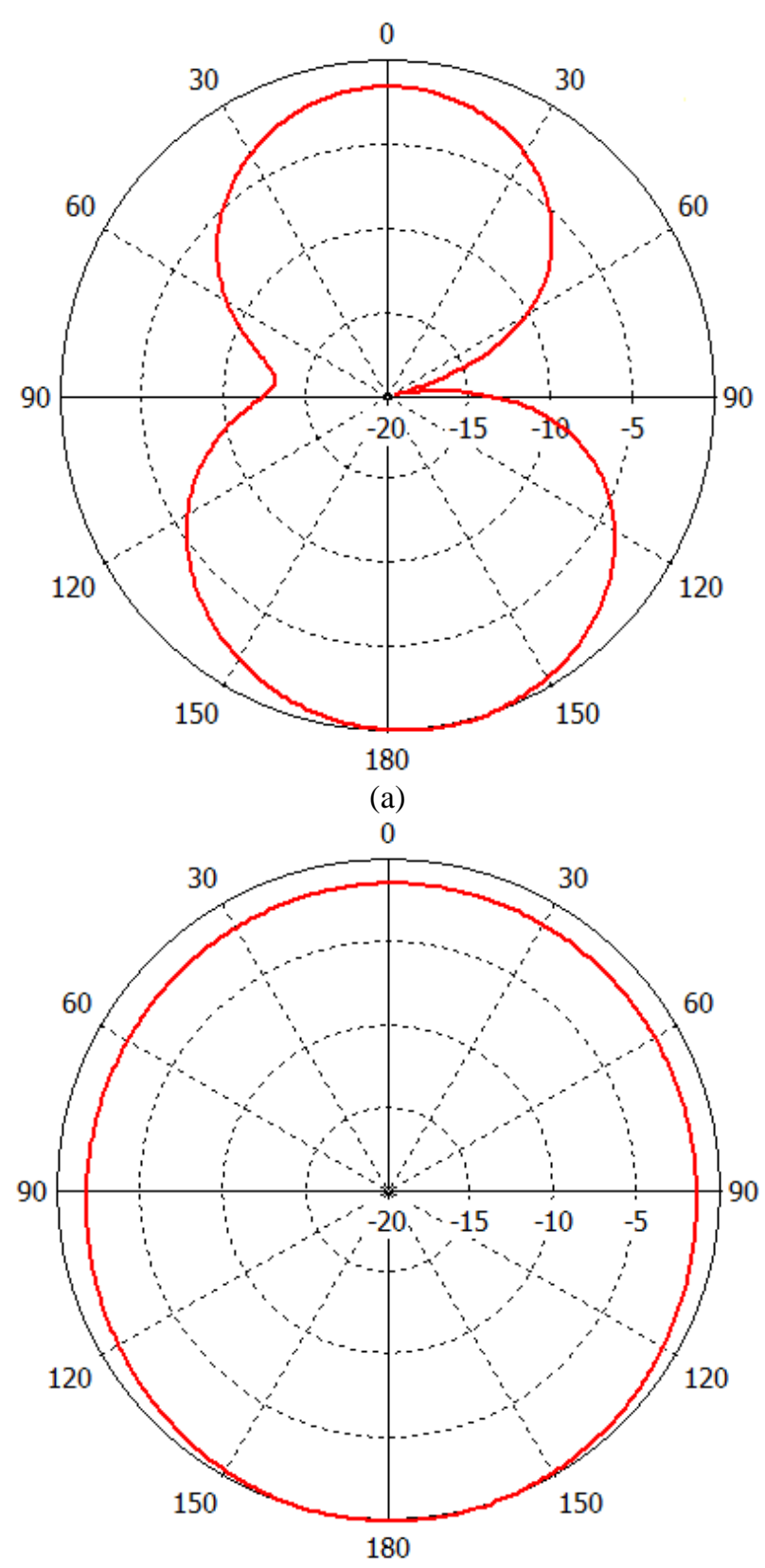

(b)

Fig. 7. Simulated normalized power pattern of the proposed moon shaped filtenna at $3.7 \mathrm{GHz}$ (a) E- plane (b) $\mathrm{H}$ - plane.

\section{Conclusion}

A compact filtenna with sharp rejection capability of the non-desired radiation outside the 5G mid-band has successfully been designed. A printed circuit antenna is combined electromagnetically with a half CLL filter to form the proposed design. In spite of its small size $(24.2 \times 27 \times$ $0.8 \mathrm{~mm}^{3}$ ), the filtenna matching and radiation characteristics are so suitable for radiating the 5G mid-band EM energy and suppressing the others that cause interference with them. The filtenna reflection coefficient has reduced values at the pass band $(3.6-3.8 \mathrm{GHz})$ that reaches to less than $-17 \mathrm{~dB}$. The omnidirectional radiation pattern of the proposed design and its compact size make the filtenna to be a superior selection for portable $5 \mathrm{G}$ mid-band gadgets.
TABLE II

The Comparison of Dielectric Constant and Size of the Proposed Filtenna and Pervious Filtennas.

\begin{tabular}{|c|c|c|}
\hline Design & $\begin{array}{c}\text { Dielectric } \\
\text { constant } \\
\varepsilon_{r}\end{array}$ & size \\
\hline The proposed Filtenna & 2.2 & $24.2 * 27$ \\
\hline $\begin{array}{c}\text { The Application of } \\
\text { Reconfigurable Filtenna in } \\
\text { Mobile Satellite Terminals } \\
\text { [17]. }\end{array}$ & 3.48 & $34.24 * 26.58$ \\
\hline $\begin{array}{c}\text { A Compact, Frequency- } \\
\text { Reconfigurable Filtenna } \\
\text { with Sharply Defined } \\
\text { Wideband and Continuously } \\
\text { Tunable Narrowband States } \\
\text { [18]. }\end{array}$ & 3.48 & $50 * 30$ \\
\hline $\begin{array}{c}\text { A Compact, Vertically } \\
\text { Integrated Duplex Filtenna } \\
\text { With Common Feeding and } \\
\text { Radiating SIW Cavities [19]. }\end{array}$ & 2.2 & $45^{*} 60$ \\
\hline $\begin{array}{c}\text { Experimentally Validated, } \\
\text { Planar, Wideband, } \\
\text { Electrically Small, } \\
\text { Monopole Filtennas Based } \\
\text { on Capacitively Loaded } \\
\text { Loop Resonator [21]. }\end{array}$ & 3.48 & $29 * 27$ \\
\hline
\end{tabular}

\section{CONFLICT OF INTEREST}

The authors have no conflict of relevant interest to this article.

\section{REFERENCES}

[1] C. A. Balanis, Antenna Theory: Analysis and Design, 3rd ed. New York, NY, USA: Wiley, 2005.

[2] D. Sarkar, K.V. Srivastava, and K. Saurav, "Antenna for Cognitive Radio Applications," IEEE Antennas and Wireless propagation litters, Vol. 13, pp. 396-399, 2014.

[3] T. Gayatri, N. Anveshkumar, and V. Sharma, "A Hexagon Slotted Circular Monopole UWB Antenna for Cognitive Radio Applications," 2020 National Conference on Emerging Trends in Information Technology and Engineering (ic-ETITE), April. 2020.

[4] J. Panda, A. Saladi, and R. Kshetrimayum, "A Compact Printed Monopole Antenna for Dual-band RFID and WLAN Applications," Radio engineering, Vol. 20, NO. 2, pp. 464-467, June 2011

[5] S. Janjarla, B. Dasgupta," Star Shaped Broadband Printed Antenna with U-Shape Ground Plane," 2020 National Conference on Emerging Trends on Sustainable Technology and Engineering applications (NCETSTEA), 18 June. 2020.

[6] T. Cheng, W. Jiang, S. Gong, and Y. Yu, "Broadband SIW Cavity-Backed Modified Dumbbell-Shaped Slot Antenna," IEEE Antennas and Wireless propagation litters, Vol. 18, Issue. 5, pp. 936-940, May 2019. 
[7] S. Ali, A. Reja, and Y. Hachim, "Design a Compact Wideband Antenna Used in Radio Frequency Identification Systems," Iraqi Journal for Electrical and Electronic Engineering, pp. 134-138, June 2020. DOI: 10.37917/ijeee.sceeer.3rd.19

[8] H. Kaur, and N. Ahuja, "Design of Single Band Slotted Microstrip Patch Antenna for WiMax Band," International Journal of Computer Applications, Vol. 67, No. 14, pp. 4043, April 2013.

[9] R. Madina, E. Rahardjo, F. Zulkifli, "Multiband Wideband Monopole Antenna using RSRR for WLAN and WiMAX Applications," 2019 IEEE Region 10 Humanitarian Technology Conference, 12-14 Nov.2019.

[10] N. Abdul Hussein, and A. Abd-Allah, "Design of a Wide Dual-Band Coplanar Probe Feed Antenna for WLANs Applications," Iraqi Journal for Electrical and Electronic Engineering, pp. 13-16 June 2020. DOI: 10.37917/ijeee.sceeer.3rd.2

[11] H. Mkindu, and H. Iddi, "Multi-Bands Circular Ring Monopole Antenna with Double L-Shape for WLAN/WiMAX Applications," Tanzania Journal of Science, Vol. 47(1), pp. 228-242, 2021.

[12] M. Abdullah, and S. Koziel, "A Novel Versatile Decoupling Structure and Expedited Inverse-Mode Based Re-Design Procedure for Compact Single- and Dual-Band MIMO Antennas," IEEE Access, Vol. 9, pp. 37656-37667, March 2021.

[13] K. Xu, H. Luyen, and N. Behdad, "A Decoupling and Matching Network Design for Single- and Dual-Band Two-Element Antennas Arrays," IEEE Transactions on Microwave Theory and Techniques, Vol. 68, Issue. 9, pp. 3986-3999, Sept. 2020.

[14] ] F. Alnahwi, Y. Al-Yasir, A. Abdulhameed, A. Abdullah, and R. Abd-Alhameed, "A Low-Cost Microwave Filter with Improved Pass band and Stop band Characteristics Using Stub Loaded Multiple Mode Resonator for 5G Mid-Band Applications," Electronics, Vol. 10, Issue. 4, February 2021.

[15] S. Lin, P. Chiou, Y. Chen, and S. Chang," An Accurate Filtenna Synthesis Approach Based on Load -Resistance Flattening and Impedance-Transforming Tapped- Feed Techniques, Vol. 6, pp. 24568-14581, 24. May 2018.

[16] R. Gómez-García, L. Yang, J. Muñoz-Ferreras, and D. Psychogio, "Selectivity-Enhancement Technique for Stepped-Impedance-Resonator Dual-Pass band Filters," IEEE Antennas and Wireless components litters, Vol. 29, No. 7, pp. 453-455, July 2019.

[17] L. Rodrigues, T. Varum, and J. Matos, "The Application of Reconfigurable Filtenna in Mobile Satellite Terminals“, IEEE Access, Vol. 8, pp. 77179-77189, 2020.

[18] M. Tang, Z. Wen, H. Wang, M. Li, and R. Ziolkowski, "A Compact, Frequency-Reconfigurable Filtenna with Sharply Defined Wideband and Continuously Tunable Narrowband States," IEEE Transactions on Antenna and Propagation, 23.June 2017.

[19] K. Hu, M. Tang, Y. Wang, D. Li, and M. Li,“ A Compact, Vertically Integrated Duplex Filtenna With Common Feeding and Radiating SIW Cavities," IEEE Transactions on Antennas and propagation , Vol. 69, Issue. 1, pp. 1-6, 2021.
[20]F. Juma'a, F. Alnahwi, "Design and Simulation of Butterfly-Shaped Filtenna with Dual Band Notch for Portable UWB Applications," Iraqi Journal for Electrical and Electronic Engineering, Vol. 17, Issue 1, pp. 1-7, June 2021.

[21] M. Tang, Y. Chen, and R. Ziolkowski, "Experimentally Validated, Planar, Wideband, Electrically Small, Monopole Filtennas Based on Capacitively Loaded Loop Resonator," IEEE Transactions on Antennas and propagation, Vol. 64, Issue. 8, pp. 1-8, Aug. 2016.

[22] D. Sarkar, K. V. Srivastava and K. Saurav, “ A compact Microstrip-Fed Triple Band-notched UWB Monopole Antenna," IEEE Antennas and Wireless Propagation Letters, Vol. 13, pp. 396-399, 2014.

[23] “CST Microwave Studio User Manual," ver. 2010, CST GmbH, Darmstadt, Germany, 2010. 